\title{
Contrast Sensitivity in Patients with Beta-Thalassemia Major and Sickle Cell Disease Under Regular Transfusions and Treatment with Desferrioxamine
} \author{
Peschos Dimitrios $^{4}$, Christodoulou Aikaterini ${ }^{2}$ and Aspiotis Miltiadis ${ }^{2}$ \\ ${ }^{1}$ Epirus Vision Center, Ioannina, Greece \\ ${ }^{2}$ Ophthalmology Department, University Hospital of Ioannina, Greece \\ ${ }^{3}$ Pediatrics Department, University Hospital of Ioannina, Greece \\ ${ }^{4}$ Physiology Department, University Hospital of Ioannina, Greece
}

Gorezis Spyridon $^{*}, 1$, Asproudis Ioannis ${ }^{2}$, Chalasios Nikolaos ${ }^{3}$, Karali Aikaterini ${ }^{3}$, Tsanou Elena ${ }^{1}$,

\begin{abstract}
Purpose: Evaluation of contrast sensitivity in patients with beta-thalassemia major and sickle cell disease which undergo regular transfusions and chelation therapy with desferrioxamine (DFX).

Materials and Methods: We studied contrast sensitivity in 48 eyes (24 patients) with beta-thalassemia major (group A) and in 42 eyes (21 patients) with sickle cell disease (group B), compared to 60 eyes of 30 healthy individuals (control group). Contrast sensitivity was measured using B-VAT II-SG Mentor Video Aquity Tester.

Results: We found no statistically significant difference between group A and group B in any spatial frequency, while we found statistically significant differences between group B and control group in all spatial frequencies studied. Between group A and control group we found statistically significant differences in spatial frequencies of 2.3 , and $6 \mathrm{cyc} / \mathrm{deg}$.

Conclusion: DFX causes retinal alterations that may explain reductions in contrast sensitivity function and justifies regular evaluations that may allow early detection of visual function deterioration.
\end{abstract}

Keywords: Contrast sensitivity, beta-thalassemia, desferrioxamine, sickle cell.

\section{INTRODUCTION}

Blood transfusion on a continual basis is the primary if not the only treatment in various refractory and aplastic anemias most notably beta-thalassemia major (BTM) and sickle cell disease (SCD) [1]. Although this can prevent death from anemia in infancy and permit normal growth and development during childhood, blood transfusions are responsible for accumulation of toxic amounts of iron in tissues which eventually leads to organ failure [2].

Desferrioxamine (diethylenetriamine penta-acetic acid) (DFX), an iron chelating agent is used extensively to maintain iron balance, however itself may cause sideffects. Ocular toxicity of DFX first came to light when four patients with BTM were treated with a high intravenous dose to counter the effects of transfusion induced iron overload [3]. Two patients developed night blindness and visual field defects which improved upon withdrawal of the drug. In the past years studies have associated high doses of DFX with lens opacities, visual loss, loss of color vision, night blindness, visual field defects, dyschromatopsia $[1,4]$.

Considering the above reports, we conducted an ophthalmologic evaluation of patients with BTM and SCD undergoing regular chelation therapy with DFO, using

*Address correspondence to this author at the Epirus Vision Center, Panepistimiou Avenue, Ioannina, 45110, Greece; Tel: +302651067689; Fax: +302651067889; E-mail: gorezis@hotmail.com contrast sensitivity to test their visual function. Recent literature regards contrast sensitivity as a more sensitive method than Snellen visual acuity testing $[5,6]$. Impaired contrast sensitivity in the presence of normal visual acuity has also been related with various retinal and optic nerve diseases [7-10]. Therefore, this method seems to be better indicated as a primary screening test for detecting early functional visual loss in patients with BTM and SCD that present with normal visual acuity in the Snellen chart.

\section{MATERIALS AND METHODOLOGY}

We studied a group of 48 eyes (24 patients) with BTM (group A) and 42 eyes (21 patients) with SCD (group B) against a control group of 60 eyes of 30 healthy individuals (control group). The study was conducted over a period of three monthes. Patients were followed at the Pediatrics Department of the University Hospital of Ioannina; they were all regularly transfused and treated by subcutaneous infusions of DFX. Specifically, in BTM the transfusions were performed depending on the gravity of the case every 1 to 3 weeks. For sickle cell anemia transfusions were performed durind aplastic crisis, splenic pooling and CNS episodes. Inclusion criteria were best corrected visual acuity of 20/20 or better and no history of any ocular disease. Control subjects were matched for age and sex with patients and were questioned for any history of ocular disease or medication that could affect contrast sensitivity evaluation. All participants underwent an ophthalmic evaluation that consisted of Snellen visual acuity evaluation, contrast 
Table 1. Age, Gender, Therapy Duration and Blood Ferritin Levels in Groups Under Study

\begin{tabular}{|c|c|c|c|}
\hline & BTM & SCD & Control Group \\
\hline Age (years) & $31,09 \pm 6,54$ & $27,75 \pm 5,49$ & $27,57 \pm 5,06$ \\
\hline DFX treatment duration (years) & $12,48 \pm 2,83$ & $11,9 \pm 2,25$ & - \\
\hline Ferritin levels (ng/mL) & $2036,17 \pm 2520,30$ & $1988,95 \pm 2974,15$ & $194,1 \pm 78,6$ \\
\hline
\end{tabular}

sensitivity evaluation, slit lamp microscopy and dilated pupil fundus examination. Fluroscein angiography was performed in all patients. Both eyes were studied separately.

The Mentor B-VAT II Video Acuity Tester (Mentor O\&O Inc., MA) generates sine wave gratings with spatial frequencies of $1.5,3,6,12$, and $18 \mathrm{cyc} / \mathrm{deg}$ and contrast levels of up to $98 \%$ on a computer processor module, which are displayed on a cathode ray tube monitor. Threshold was determined using a three-alternative forced-choice staircase procedure with a converging performance level of $70 \%$ in which patients were required to identify the orientation of gratings, which lie either vertical or obliquely oriented to the right or left by $15^{\circ}$. Stimulus contrast was reduced after two correct responses and increased after one incorrect response. Threshold was calculated as the mean of the last eight contrast reversals. The monitor was viewed from $3 \mathrm{~m}$ in a darkened room and had a mean luminance of $85 \mathrm{~cd} / \mathrm{m} 2$. v12.

Statistical analysis was performed with ANOVA in SPSS

\section{RESULTS}

A total of 150 eyes were included in our study. Fortyeight of them belonged to BTM patients, 42 to SCD patients and 60 eyes served as controls. Groups were matched for age, sex and refractive data. Mean age in years was $31,09 \pm 6,54$ for BTM patients (22 to 45$), 27,75 \pm 5,49$ for SCD patients (20 to 40 ) and $27,57 \pm 5,06$ for control group (20 to 40). Male to female ratio can be seen in Table 1 . The dose of DFX administrated to the patients was $50 \mathrm{mgr} / \mathrm{kgr} /$ day four to five days a week. Mean disease duration was $15 \pm 2,3$ years in BTM and $13 \pm 2,45$ in SCD patients. Mean treatment duration was 12, 16 $\pm 2,44$.

Slit lamp examination did not reveal any findings in any case. No macular edema or other pigmentary changes on the macula were observed in any of the cases. One patient with BTM was excluded due to angiotic streaks and 1 patient with SCD was excluded due to retinal epithelial changes.

There was no statistically significant difference between groups regarding Snellen visual acuity.

We found no statistically significant difference between group A and group B in any spatial frequency that we studied, while statistically significant differences were demonstrated between group $\mathrm{B}$ and control group in all spatial frequencies studied $(2,3,6,12,18 \mathrm{cyc} / \mathrm{deg})$. CSF values in all three groups are presented in Table 2 . Between group A and control group we found statistically significant differences in spatial frequencies of 2, 3, and 6 cyc/deg.
Table 2. CSF Values in the All Three Groups

\begin{tabular}{|c|c|c|}
\hline CSF Values (cyg/deg) & Group & Log Units \\
\hline SF $1.50 \mathrm{D}$ & $\begin{array}{l}\text { control } \\
\text { BTM } \\
\text { SCD }\end{array}$ & $\begin{array}{l}2.21 \pm 0.77 \\
1.34 \pm 0.40 \\
1.51 \pm 0.53\end{array}$ \\
\hline SF $1.50 \mathrm{~S}$ & $\begin{array}{l}\text { control } \\
\text { BTM } \\
\text { SCD }\end{array}$ & $\begin{array}{r}1.95 \pm 0.53 \\
1.41 \pm 0.61 \\
1.51 \pm 0.53\end{array}$ \\
\hline SF 3 D & $\begin{array}{l}\text { control } \\
\text { BTM } \\
\text { SCD }\end{array}$ & $\begin{array}{r}1.81 \pm 0.44 \\
1.19 \pm 0.31 \\
1.05 \pm 0.53\end{array}$ \\
\hline SF 3S & $\begin{array}{l}\text { control } \\
\text { BTM } \\
\text { SCD }\end{array}$ & $\begin{array}{r}1.72 \pm 0.54 \\
1.07 \pm 0.05 \\
1.05 \pm 0.23\end{array}$ \\
\hline SF 6 D & $\begin{array}{l}\text { control } \\
\text { BTM } \\
\text { SCD }\end{array}$ & $\begin{array}{r}1.84 \pm 0.53 \\
1.27 \pm 0.47 \\
1.41 \pm 0.47\end{array}$ \\
\hline SF $6 \mathrm{~S}$ & $\begin{array}{l}\text { control } \\
\text { BTM } \\
\text { SCD }\end{array}$ & $\begin{array}{l}1.78 \pm 0.61 \\
1.36 \pm 0.89 \\
1.41 \pm 0.47\end{array}$ \\
\hline SF $12 \mathrm{D}$ & $\begin{array}{l}\text { control } \\
\text { BTM } \\
\text { SCD }\end{array}$ & $\begin{array}{l}3.21 \pm 1.08 \\
2.63 \pm 1.14 \\
2.44 \pm 0.98\end{array}$ \\
\hline SF12 S & $\begin{array}{l}\text { control } \\
\text { BTM } \\
\text { SCD }\end{array}$ & $\begin{array}{l}3.06 \pm 1.16 \\
2.44 \pm 0.82 \\
2.44 \pm 0.98\end{array}$ \\
\hline SF18 D & $\begin{array}{l}\text { control } \\
\text { BTM } \\
\text { SCD }\end{array}$ & $\begin{array}{l}5.51 \pm 1.63 \\
5.03 \pm 2.05 \\
4.47 \pm 2.39\end{array}$ \\
\hline SF $18 \mathrm{~S}$ & $\begin{array}{l}\text { control } \\
\text { BTM } \\
\text { SCD }\end{array}$ & $\begin{array}{l}6.19 \pm 2.79 \\
6.77 \pm 3.32 \\
6.91 \pm 3.26\end{array}$ \\
\hline
\end{tabular}

\section{DISCUSSION}

Mitchell [11] shows that contrast sensitivity (CS) can better discriminate ophthalmic disease in certain populations compared to Snellen visual acuity. Woods [6] further found that CS sensitivity was more efficient in measuring visual acuity than Snellen visual acuity method as a screening technique, too. Results in our study confirm that contrast 
sensitivity can be significantly impaired in patients with BTM and patients with SCD compared to healthy individuals, while Snellen visual aquity seems unaffected. This is in accordance with previous studies reflecting the fact that early alterations in retinal physiology cause slight and difficult to detect changes in the way neuroreceptors perceive stimuli.

DFX administration has been reported to affect the eye in many ways. Correlations have been made with the age of patients or the dosage of DFX. Side effects include lens opacities, changes in the retinal pigment epithelium, tortuosity of retinal vessels, dilation and sheathing of retinal vessels. Few studies however assess functional visual loss which precedes the appearance of visible ocular changes

Contrast sensitivity is reduced compared to the control group for all spatial frequencies under study in patients with sickle cell disease and in low and medium spatial frequencies in patients with beta-thalassemia major. Important factor that may be responsible for our findings is desferioxamine's toxic effect. Toxic retinopathy is one of the complications associated with deferoxamine, in which different manifestations including pigmentary retinopathy, bull's eye maculopathy, and vitelliform maculopathy have been described [12]. Whether or not certain changes observed in the retinal pigment epithelium (RPE) cells and in Bruch's membrane are in part due to ocular siderosis, is difficult to determine. RPE changes following high doses of DFX have been microscopically confirmed through histochemical studies. Loss of microvilli from the apical surface, patchy degeneration, vacuolation of the cytoplasm, swelling and calcification of mitochondria as well as disorganization of the plasma membrane [4] were described.

Recovery when DFX is stopped and pathological reports that do not reveal iron deposition in RPE cells support toxicity of the drug. The mechanism is not completely clear. DFX as a chelating agent binds not only to iron but copper and zinc, as well, both of which are important components of retinal pigment epithelium. De Virgilis et al. [13] reported transient and permanent electroretinogram abnormalities, related to zinc and copper or iron depletion, in BTM patients receiving high doses of intravenous DFX.

In pediatric groups examined during the last years, DFOtreated patients presented rare and mild findings of ocular toxicity [14], and furthermore deferoxamine at doses lower than $50 \mathrm{mg} / \mathrm{kg} / \mathrm{d}$ was safe for the eyes and slightly toxic to the ears [15].

Under this perspective, contrast sensitivity evaluation is important in patients who receive constant, large doses of desferioxamine, in order to detect early changes in visual acuity. However it must be stressed that taking into account that the consequence of no DFX treatment is early death, the risk-benefit ratio of chelation therapy remains extremely low.
Contrast sensitivity is reduced compared to the control group for all spatial frequencies under study in patients with sickle cell disease and in low and medium spatial frequencies in patients with beta-thalassemia major. Important factor that may be responsible for our findings is deferoxamine's toxic effect.

\section{CONFLICT OF INTEREST}

Written informed consent was obtained from the patients for publication of this article.

\section{ABBREVIATIONS}

$\begin{array}{lll}\mathrm{DFX} & = & \text { Desferrioxamine } \\ \mathrm{BTM}= & \text { Beta-thalassemia major } \\ \mathrm{SCD} & = & \text { Sickle cell disease } \\ \mathrm{CNS} & = & \text { Central nervous system }\end{array}$

\section{REFERENCES}

[1] Zafeiriou DI, Kousi AA, Tsantali CT, et al. Neurophysiologic evaluation of long-term desferrioxamine therapy in betathalassemia patients. Pediatr Neurol 1998; 18: 420-4.

[2] Graziano JH, Markenson A, Miller DR, et al. Chelation therapy in beta-thalassemia major. Intravenous and subcutaneous deferoxamine. J Pediatr 1978; 92: 648-2.

[3] Davies SC, Marcus RE, Hungerford JL, Miller MH, Arden GB, Huehns ER. Ocular toxicity of high-dose intravenous desferrioxamine. Lancet 1983; 2: 181-4.

[4] Rahi AHS, Hungerford JL, Ahmed AI. Ocular toxicity of desferrioxamine: light microscopic, histochemical and ultrastructural findings. Br J Ophthalmol 1986; 70: 373-81.

[5] Regan D, Neima D. Low-contrast letter charts as a test of visual function. Ophthalmology 1983; 90: 1192-200.

[6] Woods RL, Tregear SJ, Mitchell RA. Screening for ophthalmic disease in older subjects using visual acuity and contrast sensitivity. Ophthalmology 1998; 105: 2318-26.

[7] Fiorentini A, Lamberto M. Spatial contrast sensitivity of myopic subjects. Vision Res 1976; 16: 437-8.

[8] Maraini G, Rosmini F, Graziosi P, et al. Influence of type and severity of pure forms of age-related cataract on visual acuity and contrast sensitivity. Invest Ophthalmol Vis Sci 1994; 35: 262-7.

[9] Mela EK, Gartaganis SP, Koliopoulos JX. Contrast sensitivity function after cataract extraction and intraocular lens implantation. Doc Ophthalmol 1996; 92: 79-81.

[10] Lindstrom R. Food and Drug Administration study update. Oneyear results from 671 patients with the $3 \mathrm{M}$ multifocal intraocular lens. Ophthalmology 1993; 100: 91-7.

[11] Mitchell RA. Contrast sensitivity in elderly subjects with a diagnosed ocular disease. Optom Vis Sci 1993; 70: 102-6.

[12] Lai TY, Lee GK, Chan WM, Lam DS. Rapid development of severe toxic retinopathy associated with continuous intravenous deferoxamine infusion. Br J Ophthalmol 2006; 90: 243-4.

[13] De Virgiliis S, Congia M, Frau F, et al. Deferoxamine-induced growth retardation in patients with thalassemia major. J Pediatr 1988; 113: 661-9.

[14] Baath JS, Lam WC, Kirby M, Chun A. Deferoxamine-related ocular toxicity: incidence and outcome in a pediatric population. Retina 2008; 28: 894-9.

[15] Chen SH, Liang DC, Lin HC, Cheng SY, Chen LJ, Liu HC. Auditory and visual toxicity during deferoxamine therapy in transfusion-dependent patients. J Pediatr Hematol Oncol 2005; 27: 651-3. 